\title{
TRAUMATIC PELVIC FRACTURES HOSPITALIZED IN KASR AL-AINY HOSPITAL IN 2018: A RETROSPECTIVE STUDY
}

\author{
Mohamed Adly; Hanaa Elzahed \\ Department of Forensic Medicine and Clinical Toxicology, \\ Faculty of Medicine, Cairo University
}

Mohamed Adly: mohamedadly466@gmail.com/ Tel.: 01223462419,01112611621

\begin{abstract}
Major pelvic fractures are predominantly observed when there is a highenergy transfer to the patient such as following road traffic collision, pedestrian accident, fall from height, or crush injury. Less serious pelvic fractures may occur with low-energy transfer events, particularly in the elderly. Objectives: The aim of the current study is to statistically assess the prevalence, common causes, management and outcome of pelvic fracture cases admitted to Kasr Al-Ainy hospital through the year 2018. Subjects and methods: The data presented in this study were obtained from the bureau of statistics at Kasr Al-Ainy hospital. One hundred ninety six cases with traumatic pelvic fractures were admitted to Kasr AlAiny hospital during the one year period study from January 2018 to December 2018. Results: the incidence of traumatic pelvic fractures in the present study was higher in males, urban areas and day time. The age group 21-40 was associated with a higher percentage of traumatic pelvic fractures was recorded and a mean age was 35 years. Road traffic accidents were the commonest cause followed by fall from height. A higher incidence of multiple pelvic fractures and the higher percentage of cases was treated surgically. Improvement was the major outcome while death was associated with the old age group above 61 years. Conclusion and recommendations: there is a need to decrease the number of road traffic accidents and greater precautions should be taken against the risks of fall from height. Old age group should be managed with special care.
\end{abstract}

KEYWORDS: Pelvic fractures, Kasr Al-Ainy hospital, Road traffic accidents, Fall from height.

\section{INTRODUCTION}

Pelvic ring fractures are considered uncommon fractures since the incidence is ranging from $3 \%$ to $8 \%$ of all patients subjected to trauma. Furthermore, fracture pelvis accounts for $1-3 \%$ of all skeletal fractures and constitutes $2 \%$ of orthopedic cases admitted to hospitals (Pohlemann et al., 1996; and Gustavo Parreira et al., 2000).

However, pelvic ring fractures are associated with a high mortality rate that 
varies between $4 \%$ up to $28 \%$. The associated injuries with traumatic pelvic fractures mainly and not the fracture itself account for most of the deaths in these patients (Demetriades et al., 2012; Hauschild et al., 2008; and Holstein et al., 2012). Fracture pelvis can result in excessive hemorrhage or shock due to associated punctured wound of the internal viscera such as the bladder or the bowel (Walker, 2011).

Pelvic fractures are usually the result of a high energy trauma and are associated with other injuries in about 90\% of cases (Dalal et al., 1989; and Gustavo Parreira et al., 2000). Road traffic accidents are responsible for about $80 \%$ of cases of pelvic fractures and pedestrians are more commonly involved than car occupants (Cordts Filho Rde et al., 2011; and Gansslen et al., 2012).

Fall from height is the next common cause and is responsible for about $16 \%$ of all pelvic fractures (Petaros et al., 2013; and Nasef et al., 2018). Less commonly fracture pelvis is due to machinery compression or direct hit to the pelvis (Bottlang et al., 2002; and Stover et al., 2017).

Pelvic fractures are classified according to either Tile classification or Young-Burgess classification. Tile classification is based on the integrity of the posterior sacroiliac complex, pelvic fractures range in severity from low energy injuries to life threatening unstable fractures. On the other hand, Young-Burgess classification is based on the mechanism of injury (Koo et al., 2008).

According to the site of a pelvic bone fracture, pelvic fractures are divided into: single fractures i.e. individual pelvic bone fracture and complex fracture i.e. multiple pelvic bone fractures. Diagnosis of pelvic fracture is usually made on the basis of history, clinical features and special investigations usually including Xray and CT (Hirvensalo et al., 2007).

As in many cases of skeletal fractures, traumatic pelvic fractures have been associated with several medicolegal implications such as pursuit for compensations, potential risk of sustained disabilities and claims for malpractice (Harris et al., 2008).

AIM OF THE STUDY is to statistically assess the prevalence, common causes, management and outcome of pelvic fracture cases admitted to Kasr Al-Ainy hospital through the year 2018 .

\section{SUBJECTS \&METHODS}

The current work is a retrospective study of cases admitted to Kasr Al-Ainy hospital during the period from 1 st of January to 31 st of December 2018 with a history of traumatic pelvic fractures. After obtaining an official approval from the bureau of statistic at Kasr Al-Ainy hospital, data were collected through the electronic filing system. The data collected did not include the name of the patient to ensure and prevent violation of privacy.

One hundred ninety six cases of traumatic pelvic fractures were recorded during the period of the study and the following parameters were studied:

1. Demographic criteria: 
- Age: was categorized into 4 groups: <20 years, 21-40 years, $41-60$, and $>61$ years.

- Sex: male or female.

- Residence: urban or rural areas.

2. Time of injury: day (a.m.) or night (p.m.).

3. Type of fracture: single pelvic fracture or multiple pelvic fractures.

4. Cause of fracture: car accident, motor cycle accident, fall from height, hit by solid object, or unknown.

5. Management: whether conservative or surgical.

6. Outcome:

improvement, discharge by request, escape, and death.

Inclusion criteria included all traumatic pelvic fractures with or without other injuries in the body, all age groups, and both sexes. While exclusion criteria included pelvic fractures due to pathologic causes; and pelvic fractures received at emergency department and referred to other hospitals without admission.

Statistical analysis:

The collected data were tabulated and analyzed using SPSS version 16 soft ware (SPSS Inc, Chicago, ILL Company). Categorical data were presented as number and percentages while quantitative data were expressed as mean \pm standard deviation. Chi square $\left(\mathrm{X}^{2}\right)$ test, Fisher's exact test were used as tests of significance. The accepted level of significance in this work was stated at
0.05 (P $<0.05$ was considered significant).

\section{RESULTS}

As regards the demographic results, the incidence of pelvic fractures was highest in the age group 21-40 years accounting for $36.2 \%$ of the cases followed by both the age groups <20 year and 41-60 years being $27.6 \%$ and $26 \%$ respectively. On the other hand, the incidence was lowest in the age group $>61$ years which accounted for only $10.2 \%$ of cases. The mean age \pm SD for all cases was $35.67 \pm 17.875$ (table 1). While the distribution of the hospitalized cases of fracture pelvis showed a greater prevalence among males $(61.2 \%)$ than females $(38.8 \%)$ as shown in table 2. Furthermore, pelvic fractures in the current study were higher in urban (58.2\%) than in rural areas (table 3 ).

Table 4 showed that the incidence of pelvic fractures in the present study was higher during the day $(55.1 \%)$ than in the night (44.9\%). Regarding the cause of pelvic fractures, car accidents accounted for more than half of the cases $(54.6 \%)$ followed by motorcycle accidents (19.4\%). Fall from height represented the third common cause of pelvic fractures $(17.3 \%)$ while hit by solid object was the least recorded cause (3.6\%). It should be noted that it was unknown (not registered) in $5.1 \%$ of cases (table 5). 
In the current study, multiple pelvic fractures were more common than single pelvic fractures and represented $55.1 \%$ of cases studied, while single pelvic fractures on the other hand represented $44.9 \%$ of cases (table 6). Regarding the management of the studied cases, surgical procedures accounted for $54.1 \%$ while conservative treatment accounted for the lesser portion being 45.9\% (table 7). As for the outcome, improvement constituted the most common outcome and represented $87.8 \%$, while escape from the hospital accounted for $5.6 \%$. Discharge on the request of the patient was recorded in $4.6 \%$ of the hospitalized cases, while death was recorded only in $2 \%$ of cases (table 8).

Correlation between the sex and different age groups in the current study showed that the highest percentage of males with fracture pelvis was within the age group 2140 year $(38.3 \%)$ followed by the age group $41-60$ years $(33.3 \%)$ and $<20$ years $(20 \%)$. While males within the age group $>61$ years accounted only for $8.3 \%$. On the other hand, females within the age group $<20$ years formed the higher portion of fracture pelvis $(39.5 \%)$. The age groups $21-40$ years and 41-60 years accounted for $32.9 \%$ and $14.5 \%$ respectively for pelvic fractures in females. Similar to males, age group $>61$ years accounted for the least percentage being $13.2 \%$. The probability value was significant $(\mathrm{P}=0.003) \quad$ (table 9).
As for the correlation between the sex and the type of pelvic fracture in the current study, it was shown that in males both single pelvic fracture (49.2\%) and multiple pelvic fractures $(50.8 \%)$ were almost equally distributed. While in females, multiple pelvic fractures were higher $(61.8 \%)$ than single pelvic fracture $(38.2 \%)$. However, the probability value was insignificant $(\mathrm{P}>0.05)$ (table 10).

The correlation between the different age groups and the fracture type showed that the distribution of single pelvic fractures and multiple pelvic fractures were higher in the age group 21-40 years being $42 \%$ and $31.5 \%$ respectively. While the lowest distribution was in the age group $>61$ years and both types of fractures were equally distributed within this age group $(10.2 \%)$. The probability value was not significant $(\mathrm{P}>0.05)$ (table 11).

On the other hand, the correlation between the cause of pelvic fracture and the different age groups showed that car accidents and motor cycle accidents represented the commonest causes of pelvic fracture in the age group 21-40 years being $37.4 \%$ \& $55.3 \%$. While both car accidents and motor cycle accidents were uncommon causes of fracture pelvis in the age group $>61$ years being only $10 \%$ and $0 \%$ respectively. On the other hand, fall from height as a cause of fracture pelvis was most common in the age group $<20$ years (58.8\%) followed by the age group 21-40 years $(17.6 \%)$. Moreover, fall 
from height accounted for the smallest percentage in the age group $>61$ years being only $8.8 \%$. Hit by solid object was considered only in both the age groups <20 years and $21-40$ years $(57.1 \%$ and $42.9 \%$ respectively). The probability value was highly significant $(\mathrm{P}=0.000)$ (table 12).

As for the correlation between the cause of pelvic fracture and the sex, both car accidents and motor cycle accidents were significantly higher in males and the percentage was $56.1 \%$ and $89.5 \%$ respectively. Fall from height as a cause of fracture pelvis was equally distributed between both sexes, while hit by a solid object was a commoner cause of fracture pelvis in females $(60 \%)$ than males $(40 \%)$. The probability value was found significant $(\mathrm{P}=0.002)$ (table 13).

Regarding the correlation between the fracture type and the cause of pelvic fracture, car accidents were more common associated with multiple pelvic fractures $(67.3 \%)$ while on the opposite side motor cycle accidents were mainly associated with single pelvic fractures $(68.4 \%)$. Fall from height was associated with a higher incidence of multiple pelvic fractures $(52.9 \%)$ than single pelvic fractures $(47.1 \%)$. Lastly, hit by a solid object was mainly associated with single pelvic fracture $(85.7 \%)$. The probability value was found highly significant $(\mathrm{P}=0.001)$ (table 14).

Correlation between the management and the fracture type showed that single pelvic fractures were managed mainly conservatively (93.3\%) while multiple pelvic fractures were managed mainly surgically $(96.2 \%)$. The probability values were found highly significant $(\mathrm{P}=0.000)$ as shown in table 15.

On the other hand, the correlation between the outcome and the different age groups showed that improvement was the most common outcome in the age groups 21-40 years, $<20$ years and 41-60 years being $37.2 \%, 27.3 \%$ and $26.7 \%$ respectively. On the other hand, death was associated only (100\%) with the age group $>61$ years. Discharge on request as an outcome was common with the both the age groups 21-40 years and 41-60 years and the percentage was $55.6 \%$ and $33.3 \%$ respectively. Escape from hospitalization was recorded mainly with the age group $<20$ years $(54.5 \%)$ and it was equally recorded in both age groups 21-40 years and 41-60 years $(18.2 \%)$. The probability value was highly significant $(\mathrm{P}=0.000)$ (table 16).

Correlation between the fracture type and the outcome showed no significant difference $(\mathrm{P}>0.05)$ since the improvement in cases of single pelvic fracture and cases of multiple pelvic fractures was $86.4 \%$ and $88.9 \%$ respectively. On the other hand, death percentage was $1.1 \%$ in cases of single pelvic fracture and $2.8 \%$ in cases of multiple pelvic fractures. Discharge on request was $3.4 \%$ in single pelvic fracture and $5.6 \%$ in multiple pelvic fractures. 
Lastly, escape from the hospital was higher in single pelvic fracture being
$9.1 \%$ compared to $2.8 \%$ for multiple pelvic fractures (table 17).

Table 1: Distribution of cases of traumatic pelvic fractures among different age groups

\begin{tabular}{|c|c|c|c|}
\hline $\begin{array}{c}\text { Age groups } \\
\text { in years }\end{array}$ & $\begin{array}{c}\text { Number of } \\
\text { cases }\end{array}$ & Percentage & \multirow{2}{*}{$\begin{array}{c}\text { Mean } \pm \text { SD } \\
\text { (years) }\end{array}$} \\
\cline { 1 - 2 }$<20$ & 54 & $27.6 \%$ & \multirow{2}{*}{30} \\
\cline { 1 - 2 } $21-40$ & 71 & $36.2 \%$ & \multirow{2}{*}{$35.67 \pm 17.875$} \\
\cline { 1 - 2 } $41-60$ & 51 & $26.0 \%$ & \\
\cline { 1 - 2 }$>61$ & 20 & $10.2 \%$ & \\
\cline { 1 - 2 } Total & 196 & $100.0 \%$ & \\
\hline
\end{tabular}

Table 2: Distribution of cases of traumatic pelvic fractures according to the sex

\begin{tabular}{|c|c|c|}
\hline Sex & Pelvic F & Number of cases \\
\hline Male & 120 & $61.2 \%$ \\
\hline Female & 76 & $38.8 \%$ \\
\hline Total & 196 & $100.0 \%$ \\
\hline
\end{tabular}

Table 3: Distribution of cases of traumatic pelvic fractures according to the residence

\begin{tabular}{|c|c|c|}
\hline Pelvic F & Number of cases & Percentage \\
\hline Residence & 82 & $41.8 \%$ \\
\hline Urban & 114 & $58.2 \%$ \\
\hline Total & 196 & $100.0 \%$ \\
\hline
\end{tabular}

Table 4: Distribution of cases of traumatic pelvic fractures according to time of incidence

\begin{tabular}{|c|c|c|}
\hline $\begin{array}{ll}\text { Time } & \text { Pelvic F }\end{array}$ & Number of cases & Percentage \\
\hline $\mathrm{am}$ & 108 & $55.1 \%$ \\
\hline $\mathrm{pm}$ & 88 & $44.9 \%$ \\
\hline Total & 196 & $100.0 \%$ \\
\hline
\end{tabular}


Table 5: Distribution of cases of traumatic pelvic fractures according to the cause

\begin{tabular}{|c|c|c|}
\hline Cause Pelvic F & Number of cases & Percentage \\
\hline Unknown & 10 & $5.1 \%$ \\
\hline Solid object & 7 & $3.6 \%$ \\
\hline Fall & 34 & $17.3 \%$ \\
\hline Motor cycle & 38 & $19.4 \%$ \\
\hline Car accident & 107 & $54.6 \%$ \\
\hline Total & 196 & $100.0 \%$ \\
\hline
\end{tabular}

Table 6: Distribution of cases of traumatic pelvic fractures according to the fracture type

\begin{tabular}{|c|c|c|}
\hline Practure type & Number of cases & Percentage \\
\hline Single pelvic fracture & 88 & $44.9 \%$ \\
\hline Multiple pelvic fractures & 108 & $55.1 \%$ \\
\hline Total & 196 & $100.0 \%$ \\
\hline
\end{tabular}

Table 7: Distribution of cases of traumatic pelvic fractures according to the management

\begin{tabular}{|c|c|c|}
\hline Pelvic F & Number of cases & Percentage \\
\hline Management & 90 & $45.9 \%$ \\
\hline Conservative & 106 & $54.1 \%$ \\
\hline Surgical & 196 & $100.0 \%$ \\
\hline Total &
\end{tabular}

Table 8: Distribution of cases of traumatic pelvic fractures according to the outcome

\begin{tabular}{|c|c|c|}
\hline Outcome Pelvic F & Number of cases & Percentage \\
\hline Death & 4 & $2.0 \%$ \\
\hline Improvement & 172 & $87.8 \%$ \\
\hline Discharge on request & 9 & $4.6 \%$ \\
\hline Escape & 11 & $5.6 \%$ \\
\hline Total & 196 & $100.0 \%$ \\
\hline
\end{tabular}


Table 9: Correlation between the sex and different age groups among cases of traumatic pelvic fractures

\begin{tabular}{|c|c|c|c|c|c|c|c|}
\hline & \multicolumn{4}{|c|}{ Sex } & \multirow{2}{*}{\multicolumn{2}{|c|}{ Total }} \\
\hline & & \multicolumn{2}{|c|}{ Male } & \multicolumn{2}{|c|}{ Female } & & \\
\hline & & no & $\%$ & no & $\%$ & no & $\%$ \\
\hline \multirow{4}{*}{ 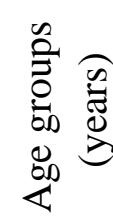 } & $<20$ & 24 & $20.0 \%$ & 30 & $39.5 \%$ & 54 & $27.6 \%$ \\
\hline & $21-40$ & 46 & $38.3 \%$ & 25 & $32.9 \%$ & 71 & $36.2 \%$ \\
\hline & $41-60$ & 40 & $33.3 \%$ & 11 & $14.5 \%$ & 51 & $26.0 \%$ \\
\hline & $>61$ & 10 & $8.3 \%$ & 10 & $13.2 \%$ & 20 & $10.2 \%$ \\
\hline \multicolumn{2}{|l|}{ Total } & 120 & $100.0 \%$ & 76 & $100.0 \%$ & 196 & $100.0 \%$ \\
\hline \multicolumn{2}{|c|}{$\mathrm{X}^{2}$} & \multicolumn{6}{|c|}{14.2} \\
\hline \multicolumn{2}{|c|}{$P$ value } & \multicolumn{6}{|c|}{$.003 *$} \\
\hline
\end{tabular}

Table 10: Correlation between the sex and the fracture type among cases of traumatic pelvic fractures

\begin{tabular}{|c|c|c|c|c|c|c|c|}
\hline & \multicolumn{4}{|c|}{ Sex } & \multirow{2}{*}{\multicolumn{2}{|c|}{ Total }} \\
\hline & & \multicolumn{2}{|c|}{ Male } & \multicolumn{2}{|c|}{ Female } & & \\
\hline & & no & $\%$ & no & $\%$ & no & $\%$ \\
\hline \multirow{2}{*}{ 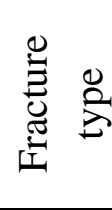 } & Single fracture & 59 & $49.2 \%$ & 29 & $38.2 \%$ & 88 & $44.9 \%$ \\
\hline & $\begin{array}{l}\text { Multiple } \\
\text { fractures }\end{array}$ & 61 & $50.8 \%$ & 47 & $61.8 \%$ & 108 & $55.1 \%$ \\
\hline \multicolumn{2}{|l|}{ Total } & 120 & $100.0 \%$ & 76 & $100.0 \%$ & 196 & $100.0 \%$ \\
\hline \multicolumn{2}{|l|}{$X^{2}$} & \multicolumn{6}{|c|}{2.2} \\
\hline \multicolumn{2}{|c|}{$\mathrm{P}$ value } & \multicolumn{6}{|c|}{$>0.05$} \\
\hline
\end{tabular}

Table 11: Correlation between the different age groups and the fracture type among cases of traumatic pelvic fractures

\begin{tabular}{|c|c|c|c|c|c|c|c|}
\hline & \multicolumn{4}{|c|}{ Fracture type } & \multirow{2}{*}{\multicolumn{2}{|c|}{ Total }} \\
\hline & & \multicolumn{2}{|c|}{ Single pelvic fracture } & \multicolumn{2}{|c|}{ Multiple pelvic fractures } & & \\
\hline & & no & $\%$ & no & $\%$ & no & $\%$ \\
\hline \multirow{4}{*}{ 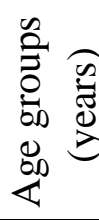 } & $<20$ & 22 & $25.0 \%$ & 32 & $29.6 \%$ & 54 & $27.6 \%$ \\
\hline & $21-40$ & 37 & $42.0 \%$ & 34 & $31.5 \%$ & 71 & $36.2 \%$ \\
\hline & $41-60$ & 20 & $22.7 \%$ & 31 & $28.7 \%$ & 51 & $26.0 \%$ \\
\hline & $>61$ & 9 & $10.2 \%$ & 11 & $10.2 \%$ & 20 & $10.2 \%$ \\
\hline \multicolumn{2}{|l|}{ Total } & 88 & $100.0 \%$ & 108 & $100.0 \%$ & 196 & $100.0 \%$ \\
\hline \multicolumn{2}{|l|}{$X^{2}$} & \multicolumn{6}{|c|}{2.5} \\
\hline \multicolumn{2}{|c|}{$\mathrm{P}$ value } & \multicolumn{6}{|c|}{$>0.05$} \\
\hline
\end{tabular}


Table 12: Correlation between the cause and the different age groups type among cases of traumatic pelvic fractures

\begin{tabular}{|c|c|c|c|c|c|c|c|c|c|c|c|c|c|}
\hline & \multicolumn{10}{|c|}{ Cause } & \multirow{2}{*}{\multicolumn{2}{|c|}{ Total }} \\
\hline & & \multicolumn{2}{|c|}{ Unknown } & \multicolumn{2}{|c|}{ Solid object } & \multicolumn{2}{|r|}{ Fall } & \multicolumn{2}{|c|}{ Motor cycle } & \multicolumn{2}{|c|}{ Car accident } & & \\
\hline & & no & $\%$ & no & $\%$ & no & $\%$ & no & $\%$ & no & $\%$ & no & $\%$ \\
\hline \multirow{4}{*}{ 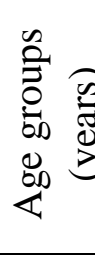 } & $<20$ & 0 & $0.0 \%$ & 4 & $57.1 \%$ & 20 & $58.8 \%$ & 9 & $23.7 \%$ & 21 & $19.6 \%$ & 54 & $27.6 \%$ \\
\hline & $21-40$ & 1 & $10.0 \%$ & 3 & $42.9 \%$ & 6 & $17.6 \%$ & 21 & $55.3 \%$ & 40 & $37.4 \%$ & 71 & $36.2 \%$ \\
\hline & $41-60$ & 2 & $20.0 \%$ & 0 & $0.0 \%$ & 5 & $14.7 \%$ & 8 & $21.1 \%$ & 36 & $33.6 \%$ & 51 & $26.0 \%$ \\
\hline & $>61$ & 7 & $70.0 \%$ & 0 & $0.0 \%$ & 3 & $8.8 \%$ & 0 & $0.0 \%$ & 10 & $9.3 \%$ & 20 & $10.2 \%$ \\
\hline \multicolumn{2}{|c|}{ Total } & 10 & $100.0 \%$ & 7 & $100.0 \%$ & 34 & $100.0 \%$ & 38 & $100.0 \%$ & 107 & $100.0 \%$ & 196 & $100.0 \%$ \\
\hline \multicolumn{2}{|c|}{ Fisher exact } & \multicolumn{12}{|c|}{74.9} \\
\hline \multicolumn{2}{|c|}{$P$ value } & \multicolumn{12}{|c|}{$.000 *$} \\
\hline
\end{tabular}

Table 13: Correlation between the cause and the sex among cases of traumatic pelvic fractures

\begin{tabular}{|c|c|c|c|c|c|c|c|c|c|c|c|c|c|}
\hline & \multicolumn{10}{|c|}{ Cause } & \multirow{2}{*}{\multicolumn{2}{|c|}{ Total }} \\
\hline & & \multicolumn{2}{|c|}{ Unknown } & \multicolumn{2}{|c|}{ Solid object } & \multicolumn{2}{|c|}{ Fall } & \multicolumn{2}{|c|}{ Motor cycle } & \multicolumn{2}{|c|}{ Car accident } & & \\
\hline & & no & $\%$ & no & $\%$ & no & $\%$ & no & $\%$ & no & $\%$ & no & $\%$ \\
\hline \multirow{2}{*}{$\stackrel{\star 凶}{\varpi}$} & M & 6 & $60.0 \%$ & 3 & $42.9 \%$ & 17 & $50.0 \%$ & 34 & $89.5 \%$ & 60 & $56.1 \%$ & 120 & $61.2 \%$ \\
\hline & $\mathrm{F}$ & 4 & $40.0 \%$ & 4 & $57.1 \%$ & 17 & $50.0 \%$ & 4 & $10.5 \%$ & 47 & $43.9 \%$ & 76 & $38.8 \%$ \\
\hline \multicolumn{2}{|c|}{ Total } & 10 & $100.0 \%$ & 7 & $100.0 \%$ & 34 & $100.0 \%$ & 38 & $100.0 \%$ & 107 & $100.0 \%$ & 196 & $100.0 \%$ \\
\hline \multicolumn{2}{|c|}{$\begin{array}{l}\text { Fisher } \\
\text { exact }\end{array}$} & \multicolumn{12}{|c|}{16.8} \\
\hline \multicolumn{2}{|c|}{$P$ value } & \multicolumn{12}{|c|}{$.002 *$} \\
\hline
\end{tabular}


Table 14: Correlation between the fracture type and the cause among cases of traumatic pelvic fractures

\begin{tabular}{|c|c|c|c|c|c|c|c|}
\hline & \multicolumn{4}{|c|}{ Fracture type } & \multirow{2}{*}{\multicolumn{2}{|c|}{ Total }} \\
\hline & & \multicolumn{2}{|c|}{ Single pelvic fracture } & \multicolumn{2}{|c|}{ Multiple pelvic fractures } & & \\
\hline & & no & $\%$ & no & $\%$ & no & $\%$ \\
\hline \multirow{5}{*}{$\begin{array}{l}\mathscr{E} \\
\tilde{\Xi} \\
\tilde{U}\end{array}$} & Unknown & 5 & $50.0 \%$ & 5 & $50.0 \%$ & 10 & $100.0 \%$ \\
\hline & solid object & 6 & $85.7 \%$ & 1 & $14.3 \%$ & 7 & $100.0 \%$ \\
\hline & Fall & 16 & $47.1 \%$ & 18 & $52.9 \%$ & 34 & $100.0 \%$ \\
\hline & Motor cycle & 26 & $68.4 \%$ & 12 & $31.6 \%$ & 38 & $100.0 \%$ \\
\hline & Car accident & 35 & $32.7 \%$ & 72 & $67.3 \%$ & 107 & $100.0 \%$ \\
\hline \multicolumn{2}{|c|}{ Total } & 88 & $44.9 \%$ & 108 & $55.1 \%$ & 196 & $100.0 \%$ \\
\hline \multicolumn{2}{|c|}{$X^{2}$} & \multicolumn{6}{|c|}{19.8} \\
\hline \multicolumn{2}{|c|}{$P$ value } & \multicolumn{6}{|c|}{$.001 *$} \\
\hline
\end{tabular}

Table 15: Correlation between the management and the fracture type among cases of traumatic pelvic fractures

\begin{tabular}{|c|c|c|c|c|c|c|}
\hline & \multicolumn{4}{|c|}{ Management } & \multirow{2}{*}{\multicolumn{2}{|c|}{ Total }} \\
\hline & \multicolumn{2}{|c|}{ Conservative } & \multicolumn{2}{|c|}{ Surgical } & & \\
\hline & no & $\%$ & no & $\%$ & no & $\%$ \\
\hline 总 & 84 & $93.3 \%$ & 4 & $3.8 \%$ & 88 & $44.9 \%$ \\
\hline of Multiple pelvic fractures & 6 & $6.7 \%$ & 102 & $96.2 \%$ & 108 & $55.1 \%$ \\
\hline Total & 90 & $100.0 \%$ & 106 & $100.0 \%$ & 196 & $100.0 \%$ \\
\hline$X^{2}$ & \multicolumn{6}{|c|}{157.8} \\
\hline$P$ value & \multicolumn{6}{|c|}{$.000 *$} \\
\hline
\end{tabular}


Table 16: Correlation between the outcome and the different age groups among cases of traumatic pelvic

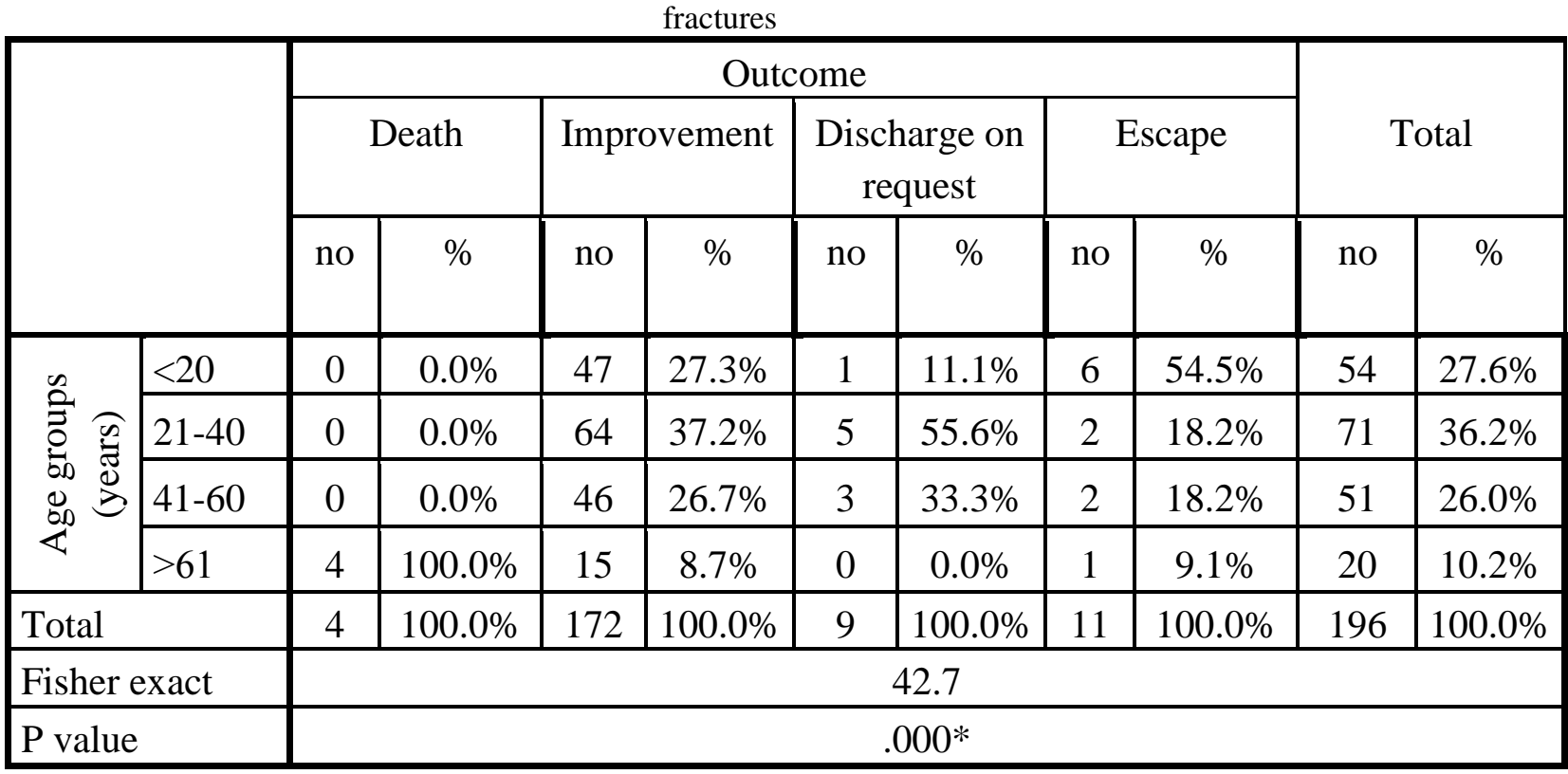

Table 17: Correlation between the fracture type and the outcome among cases of traumatic pelvic fractures

\begin{tabular}{|c|c|c|c|c|c|c|c|}
\hline & \multicolumn{4}{|c|}{ Fracture type } & & \\
\hline & & \multicolumn{2}{|c|}{$\begin{array}{l}\text { Single pelvic } \\
\text { fracture }\end{array}$} & \multicolumn{2}{|c|}{$\begin{array}{c}\text { Multiple pelvic } \\
\text { fractures }\end{array}$} & \multicolumn{2}{|c|}{ Total } \\
\hline & & no & $\%$ & no & $\%$ & no & $\%$ \\
\hline \multirow{4}{*}{ 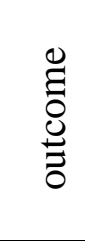 } & Death & 1 & $1.1 \%$ & 3 & $2.8 \%$ & 4 & $2.0 \%$ \\
\hline & Improvement & 76 & $86.4 \%$ & 96 & $88.9 \%$ & 172 & $87.8 \%$ \\
\hline & Discharge on request & 3 & $3.4 \%$ & 6 & $5.6 \%$ & 9 & $4.6 \%$ \\
\hline & Escape & 8 & $9.1 \%$ & 3 & $2.8 \%$ & 11 & $5.6 \%$ \\
\hline \multicolumn{2}{|c|}{ Total } & 88 & $100.0 \%$ & 108 & $100.0 \%$ & 196 & $100.0 \%$ \\
\hline \multicolumn{2}{|l|}{$X^{2}$} & \multicolumn{6}{|c|}{4.6} \\
\hline \multicolumn{2}{|c|}{$P$ value } & \multicolumn{6}{|c|}{$>0.05$} \\
\hline
\end{tabular}

\section{DISCUSSION}

Fractures of the pelvic ring have been reported to account for about $8 \%$ of all skeletal injuries and they are commonly associated with high energy trauma, most commonly car accidents, motor cycle accidents and falls from a height (Dalal et al., 1989, Gänsslen et al., 1996; and Gustavo Parreira et al., 2000).

The incidence of pelvic fracture in the few last decades seems to be increasing which can be attributed to the increases in the number of highspeed motor vehicle accidents. It was 
observed that among multiply injured patients with blunt trauma the incidence of pelvic injury was approximately 20\% (Amjad et al., 2014; and Bakhshayesh et al., 2018).

In the current study, the middle age group (21-40 years and 41-60 years) accounted for about $60 \%$ of traumatic pelvic fractures and the incidence in the old age group ( $>60$ years) was the lowest. The mean age \pm SD of the studied cases was 35.67 \pm 17.875 years. This can be explained by the fact that the middle age group is exposed to increased risk of road traffic accidents and also child supervision is documented as an important factor of injury prevention (Valerio et al., 2010; and Pressley et al., 2011). The current results are in concordance with the study conducted by Bharti, et al. (2014) which showed that the most affected age group was those between 20 and 59 years. Similar results were recorded by Durkee et al. (2006) who found that the middle age group was associated with the highest incidence of traumatic pelvic fractures and the mean age was 45.9 years. On the other hand, Korovessis et al. (2000) stated that pelvic fractures occur in bimodal pattern and the peak was in the age group 2040 and old age group over 65 years.

The incidence of traumatic pelvic fractures in the present study was higher in males to females and the ratio was approximately $3: 2$. This can be attributed to car and motor cycle accidents being more common in males due to higher speed, substance abuse and being more commonly the driver especially of motor cycles (WHO, 2013). Similar results were recorded by Gruen et al. (2009) and the ratio of pelvic fracture between males and females was 2.1: 1 . Furthermore, Furey et al. (2009) stated in their study that the percentage of pelvic fractures was $70 \%$ in males against $30 \%$ in females. Harvie et al. (2008) recorded that traumatic pelvic fractures were more prevalent in males but the incidence was $88.3 \%$ compared to $11.7 \%$ for females. This incidence is much greater than that in the present study.

Similarly, the hospitalized cases of traumatic pelvic fractures in the current study were more in urban than in rural areas and the ratio was approximately $3: 2$. This can be explained on the basis of the higher speed, high volume of traffic and the high prevalence of public transportation vehicles, pedestrian \& cyclist persons. In addition, the Kasr El-Ainy hospital is located in an urban area. Gustavo Parreira et al., 2000 also concluded that pelvic fractures were more common in urban than rural areas. Similar result was recorded by a study carried by Dente et al. (2005) which showed that urban areas were associated with a higher incidence of pelvic fractures than rural areas. On the opposite side, O'Sullivan et al. (2005) showed that the incidence of traumatic pelvic fractures was more common in rural 
area compared to urban areas and the ratio was 3:2. In addition, Brown et al. (2000) reported that motor vehicle crashes in rural areas were still significantly more fatal than in urban areas.

The time of occurrence the traumatic pelvic fracture in this study showed that the higher incidence of pelvic fractures was during the day time i.e. 55.1\%. This can be explained by the fact that rush hours are mainly in the morning with a higher incidence of motor vehicle and motor cycle crashes. This was in agreement with Blackmore et al. (2003) who found that most of pelvic fractures occurred during day time $(71.6 \%)$. In addition, Osterhoff et al. (2014) in their study stated that majority of pelvic fracture cases occurred during the morning.

In the present study, the most common cause of traumatic pelvic fractures was road traffic accidents (car and motor cycle accidents) and accounted for $74 \%$ of cases while fall from height came next $(17.3 \%)$ and lastly hit by solid object $(3.6 \%)$. This can be attributed to the high energy impact associated with road traffic accidents (Walker et al., 2011; and Hao et al., 2016). In agreement with the current results, Walker et al., 2011 stated that traffic accidents due to both car and motor cycle accidents accounted for $63 \%$ of cases of traumatic pelvic fractures while fall from height accounted for $20 \%$ of cases. Furthermore, Hao et al., 2016 showed that car and motor cycle accidents were primary causes of fracture pelvis and the rate was $53.3 \%$ \& $13.3 \%$ respectively, while fall from height accounted for $13.3 \%$.

In the current study, the incidence of multiple pelvic fractures was more common than single pelvic fracture. The present result can be attributed to the fact that multiple pelvic fractures are associated more commonly with the high energy impact which is mainly associated with road traffic accidents (Walker et al., 2011). This was in agreement with Pennal et al., 2012 who stated that pelvic fracture was a part of multiple trauma and in $58 \%$ of cases there was a sacroiliac widening while $15 \%$ presented as a single fracture site. On the other hand, Lee \& Porter, 2007 showed that multiple pelvic fractures accounted only for $33.8 \%$ of cases of fracture pelvis in their study. In addition, Abulfotooh, 1983 stated that single fracture of the pelvis with or without disruption of pelvic ring constituted the majority of traumatic pelvic fractures while multiple fractures of the pelvis constituted $10.8 \%$.

The management of traumatic pelvic fractures in the present study showed that surgical interference was more $(54.1 \%)$ than conservative treatment $(44.9 \%)$ since car accidents was a major cause of unstable multiple pelvic fractures. This is in agreement with Keykhosro \& Mahtab (2013) who described 
surgical treatment by open reduction and internal fixation an efficient management for unstable pelvic fractures. On the other hand, Eberbach et al., 2017 stated in their study that conservative treatment showed a higher success rate over surgical treatment in cases of traumatic pelvic fractures.

Improvement was the most common outcome (87.8\%) while death accounted for only $2 \%$ of cases with traumatic pelvic fractures. In agreement with the present study, Hak et al. (2009) showed that improvement and excellent clinical outcomes were achieved in $83 \%$, $11.3 \%$ showed no improvement and in $5.7 \%$ death was the result. Similarly, Papadopoulos et al. (2006) stated that the outcome was excellent in $62.4 \%$, good in $28.5 \%$ and death in $9.1 \%$. On the other hand, the rate of death from traumatic pelvic fracture was very high in the study carried by Vigdorchik et al. (2012) and it was $32 \%$.

In the present study, significant correlation was found between the sex and different age groups. Traumatic pelvic fractures in males were highest in the age group 21-40 years $(38.3 \%)$ followed by the age group 41-60 year (33.3\%), while in females it was highest in the age group $<20$ year $(39.5 \%)$ followed by the age group 21-40 years (32.9\%). In agreement with the present results, Papadopoulos et al., 2006 found that male patients with pelvic fractures were $56.3 \%$ between $20-40$ years, and $28.4 \%$ were $>40$ years, while in females it was $68 \%$ in age group $>40$ years and $22.7 \%$ between age group 20-40 years. However, the study conducted by Tyson et al. (2014) found that $50 \%$ of cases with pelvic fractures were males between 20-40 years compared to females $61.1 \%$ in the same age group.

On the other hand, the correlation between the sex and the type of pelvic fracture in the current study was insignificant, and both types of traumatic fracture pelvis were almost equally distributed in males while multiple pelvic fractures were higher than single pelvic fracture in females. Similarly, Sharma et al. (2008) in their study showed that $50 \%$ of male cases had multiple pelvic fractures.

Likewise, the correlation between the different age groups and the fracture type was insignificant. The distribution of single pelvic fracture and multiple pelvic fractures were higher in the age group 21-40 years and minimum in the age group $>60$ years. In concordance with the present study, Morozumi et al. (2010) described similar results and the peak of multiple pelvic fractures was in the age group 25-45 years. In contrast, Sathy et al. (2009) showed that $38.4 \%$ of cases $<20$ years had multiple pelvic fractures and $30 \%$ of cases were between $20-40$ years. In addition, Korovessis et al. (2000) stated that the peak of pelvic fractures 
occurred in the age group 20-40 years and age group over 65 years.

In the current study, there was a highly significant correlation between the cause of pelvic fracture and the different age groups. The age group 21-40 years was associated with higher incidence of traumatic pelvic fractures $(36.2 \%)$ and road traffic accidents (car and motor cycle accidents) were the most common cause followed by fall from height then hit by solid object. This was in agreement with the studies carried by Suzuki et al. (2007) and Hao et al. (2016) that described that traffic accidents accounted for about two thirds of cases of pelvic fractures followed by fall from height. In addition, Kreig et al. (2005) showed that the most frequent cause of pelvic injury was a road traffic accident.

A significant correlation was found between the cause of pelvic fracture and the sex. Both car accidents and motor cycle accidents were significantly higher in males while fall from height was equally distributed between both sexes. In agreement with the present study, Mauffrey (2014) showed that $44 \%$ of cases of pelvic fracture in males were due to car accident and $30 \%$ were due to fall from height. On the other hand, car accidents accounted for $40 \%$ in females followed by fall from height $(38 \%)$.

In the current study, the correlation between the fracture type and the cause of pelvic fracture was highly significant. Car accidents and fall from height were associated more commonly with multiple pelvic fractures. On the other hand, motor cycle accidents were associated mainly with single pelvic fracture. In concordance with the present results, Martin \& Tomas (2011) in their study showed that multiple pelvic ring fractures were the result of highenergy mechanisms as car accidents and fall from height.

In the present study, the correlation between the management and the fracture type was highly significant and showed that the management was mainly conservative in single pelvic fracture and surgical in multiple pelvic fractures. This was in agreement with Keykhosro \& Mahtab (2013) who preferred surgical treatment in management of unstable multiple pelvic fractures.

The correlation between the outcome and the different age groups was highly significant. Improvement was the most common outcome in all the age groups being $37.2 \%, 27.3 \%$ and $26.7 \%$ in the age groups $21-40$ years, <20 years and 41-60 years. On the other hand, death was associated only with the age group $>61$ years. Similarly, Papadopoulos et al. (2006) showed that improvement of traumatic pelvic fractures constituted the major outcome in most of the age groups in their study. In addition, Bakhshavesh et al. (2018) in a 
recent study found that the rate of mortality was higher mainly in old age group (above 60 years) in cases of pelvic fracture associated with high energy trauma. In contrast, the study conducted by Brandes \& Borrelli (2011) showed no significant difference in the outcome of traumatic pelvic fractures between different age groups included in their study.

\section{RECOMMENDATIONS}

- Increasing the efforts and raising the awareness against road traffic accidents and fall from height since both are the main causes of traumatic pelvic fracture especially in the middle age group.

- Special care should be provided to old persons above 60 years with fracture pelvis since all the deaths in the current study were in this age group.

\section{ACKNOWLEDGMENT}

We would like to express our deepest gratitude to Dr. Hala A. Abed lecturer of research and biostatistics at Public Health Department, Faculty of Medicine, Benha University for carrying the effort of the statistical analysis in the present study.

\section{REFERENCES}

Abulfotooh M E. (1983). Fractures of the pelvis. Postgraduate Medical Journal (September 1983) 59, 560-565.

Amjad, B U, Zaida B, Sarah D B et al. (2014): classification, and diagnosis of pelvic fracture: The incidence, causes, mechanism, risk factors, classification, and diagnosis of pelvic fracture. $\mathbf{J}$ Bone Joint Surg, 91: 43-47.

Bakhshavesh P, Weidenhielm L, Enocson A. (2018). Factors affecting mortality and reoperations in high energy pelvic fractures. Eur J Surg Traumatol., 28(7): 1273-1282.

Bakhshayesh P, Weidenhielm L, Enocson A. (2018). Factors affecting mortality and reoperations in highenergy pelvic fractures. Eur J Orthop Surg Traumatol. 2018 Oct; 28 (7):1273-1282.

Bharti, K, Scott E, Sheehan D et al. (2014): Pelvic Ring Fractures: What the Orthopedic Surgeon Wants to Know. Injury, 126: 855859.

Blackmore C C, Jurkovich, G J, Linnau K F et al. (2003). Assessment of volume of hemorrhage and outcome from pelvic fracture. Arch Surg. 138: 504-8.

Bottlang M, Simpson T, Sigg J, Krieg J C, Madey S M, Long W B. (2002). Noninvasive reduction of openbook pelvic fractures by circumferential compression. $\mathbf{J}$ Orthop Trauma; 16(6):367-73.

Brandes S and Borrelli J. (2011): Pelvic fracture and associated urologic injuries. World J Surg, 25:1578-87.

Brown L H, Khanna A, Hunt R C. (2000). Rural vs urban motor vehicle crash death rates: 20 
years of FARS data. Prehosp

Emerg Care;4 (1):7-13.

Cordts Filho Rde M, Parreira J

G, Perlingeiro J A, Soldá S

C, Campos T d, Assef J C

(2011). Pelvic fractures as a

marker of injury severity in trauma patients. Rev Col Bras Cir.; Sep-Oct;38(5):310-6.

Dalal S A, Burgess A R, Siegel J H, Young J W, Brumback $\mathbf{R} \mathbf{J}$, Poka A, et al. (1989). Pelvic fracture in multiple trauma: classification by mechanism is key to pattern of organ injury, resuscitative requirements, and outcome. J Trauma; 29(7):9811000; discussion 1000-2.

Demetriades D, Karaiskakis $M$, Toutouzas K, Alo K, Velmahos G, and Chan L (2002). "Pelvic fractures: epidemiology and predictors of associated abdominal injuries and outcomes," Journal of the American College of Surgeons, vol. 195, no. 1, pp. 1-10.

Dente C J, Feliciano D V, Rozycki G S, Wyrzykowski A D, Nicholas J M, Salomone J P, Ingram W L. (2005). The outcome of open pelvic fractures in the modern era. Am J Surg. 2005 Dec; 190(6):830-5.

Durkee N, Jacobson J, Jamadar D, Karunakar

Y, Hayes MA, Morag

Classification of

Acetabular

Radiographic
C. (2006).
of Common Fractures: and $\quad \mathrm{CT}$
Appearances. AJR Am J Roentgenol.; 187: 915-925.

Eberbach H, Hohloch L, Feucht M J, Konstantinidis L, Südkamp N P, Zwingmann J. (2017). Operative versus conservative treatment of apophyseal avulsion fractures of the pelvis in the adolescents: a systematical review with metaanalysis of clinical outcome and return to sports. BMC Musculoskelet Disord. 2017 Apr 19;18(1):162.

Furey A J, O'Toole R V, Nascone, J W et al. (2009). Classification of pelvic fractures: analysis of interand intra-observer variability using the Young-Burgess and Tile classification systems. Orthopedics, 32(6): 401-465.

Gansslen A, Pohleman, T; Paul, C et al. (2012): Epidemiology of pelvic ring fractures. Injury, 27: 13-20.

Gänsslen A, Pohlemann T, Paul C, Lobenhoffer $\mathbf{P}$, Tscherne $\mathbf{H}$. (1996). Epidemiology of pelvic ring injuries. Injury; 27 Suppl 1: S-A13-20.

Gruen, G S, Leit M E, Gruen, R J et al. (2009). Functional outcomes of patients with unstable pelvic-ring fractures with open reduction and internal fixation. J Trauma, 39(5):838-44.

Gustavo Parreira J, Coimbra R, Rasslan S, Oliveira A, Fregoneze M, Mercadante $M$. (2000). The role of associated injuries on outcome of blunt 
trauma patients sustaining pelvic fratures. Injury; 31(9):677-82.

Hak D J, Smith W R, Suzuki T. (2009). Management of hemorrhage in life-threatening pelvic fracture. $\mathrm{J}$ Am Acad Orthop Surg, 17: 447-457.

Hao Wang, Richard D, Robinson S et al. (2016). Pelvic fractures: incidence, management, outcome. Journal of Trauma, 2427.

Harris I A, Young J M, Jalaludin B B, Solomon M J (2008). The effect of compensation on general health in patients sustaining fractures in motor vehicle trauma. J Orthop Trauma; 22(4):216-20.

Harvie P, Chesser T J, Ward, A J. (2008). The Bristol regional pelvic and acetabular fracture service: workload implications of managing the polytraumatised patient. Injury, 39: 839-43.

Hauschild O., P. C. Strohm, U. Culemann et al., (2008). "Mortality in patients with pelvic fractures: results from the German pelvic injury register," Journal of TraumaInjury, Infection and Critical Care, vol. 64, no. 2, pp. 449455.

Hirvensalo E, Lindahl J, Kiljunen V. (2007): Modified and new approaches for pelvic and acetabular surgery. Injury, 38: 431-41.

Holstein J H, Culemann U, and Pohlemann T (2012). "What are predictors of mortality in patients with pelvic fractures?" Clinical Orthopaedics and Related Research, vol. 470, pp. 20902097.

Keykhosro $M$ and Mahtab $R$. (2013). The outcome of surgically treated traumatic unstable pelvic fractures by open reduction and internal fixation. $\mathbf{J}$ Inj Violence Res. 2013 Jun; 5(2): 77-83.

Koo H, Leveridge M, Thompson C et al. (2008): Interobserver reliability of the young-burgess and tile classification systems for fractures of the pelvic ring. $J$ Orthop Trauma, 22: 379-84.

Korovessis P, Baikousis A, Stamatakis $M$, Katonis $\mathbf{P}$. (2000). Medium- and long-term results of open reduction and internal fixation for unstable pelvic ring fractures. Orthopedics. 2000 Nov; 23(11):1165-71.

Kreig J C, Mohr M, Ellis T J et al. (2005). Emergent stabilization of pelvic ring injuries by controlled circumferential compression: a clinical trial. J Trauma volume, 59: 659-664.

Lee C and Porter K. (2007). The prehospital management of pelvic fractures. Emergency medicine journal, 24 (2): 130-134.

Martin S and Tomas P. (2011). Pelvic ring injuries: current concepts of management. Cas Lek Cesk, 150(8): 433-7.

Morozumi J, Homma H, Ohta S et al. (2010). Impact of mobile angiography in the emergency 
department for controlling pelvic fracture hemorrhage with hemodynamic instability. J Trauma, Volume 68: 90-95.

Nasef H, Elhessy A, Abushaban F, Alhammoud A. (2018). Pelvic fracture instabilityassociated L5 transverse process fracture, fact or myth? A systematic review and metaanalysis. Eur J Orthop Surg Traumatol.; 28(5):885-891.

Osterhoff G, Scheyerer M J, Fritz Y et al. (2014). Comparing the predictive value of the pelvic ring injury classification systems by Tile and by Young and Burgess. Mech, 45: 742-747.

O'Sullivan R E, White $\mathbf{T}$ O, Keating J F. (2005): Major pelvic fractures: identification of patients at high risk. J Bone Joint Surg, 87(4): 530-3.

Papadopoulos I N, Kanakaris N, Bonovas S et al. (2006). Auditing 655 fatalities with pelvic fractures by autopsy as a basis to evaluate trauma care. $\mathbf{J}$ Am Coll Surg, 203(1): 30-43.

Pennal GF, Tile M, Waddell JP et al. (2012). Pelvic disruption: Assessment and classification. Clin Orthop, 151: 12-21.

Petaros A, Slaus M, Coklo M, Sosa I, Cengija M, Bosnar A. (2013). Retrospective analysis of freefall fractures with regard to height and cause of fall. Forensic Sci Int. 2013 Mar 10; 226(1-3):290-5.

Pohlemann T, Gansslen A, Schellwald O, Culemann U,
Tscherne H. (1996). Outcome after pelvic ring injuries. Injury; 27 Suppl 2: B31-8.

Pressley J C, Kendig T D, Frencher S K, Barlow B, Quitel L, Waqar F (2011). Epidemiology of bone fracture ac ross the age span in blacks and $\mathrm{w}$ hites. J Trauma; 71 (5 Suppl 2):S541-8.

Sathy A K, Starr A J, Smith W R et al. (2009). The effect of pelvic fracture on mortality after trauma: an analysis of 63,000 trauma patients. The Journal of bone and joint surgery American, 91(12): 2803-2810.

Sharma O P, Oswanski M F, Rabbi J et al. (2008). Pelvic fracture risk assessment on admission. Am Surg, 74(8): 761-6.

Stover M D, Edelstein A I, Matta J M. (2017). Chronic Anterior Pelvic Instability:

Diagnosis and Management. J Am Acad Orthop Surg.; 25(7):509-517.

Tyson T S. (2014). Open Pelvic Fracture Due to Crush Injury. The Journal of the American Osteopathic Association urethral injury. Elsevier, London, U.K.: 28-37.

Valerio G, Galle F, Mancusi C, et al. (2010). Patterns of fracture across pediatric age groups: analysis of individual and lifestyle factors. BMC Public Health;10:656.

Vigdorchik J M, Esquivel A O, Jin X, et al. (2012). Biomechanical stability of a supra-acetabular 
pedicle screw Internal Fixation device (INFIX) vs External Fixation and plates for vertically unstable pelvic fractures. J Orthop Surg Res, 27: 7-31.

Walker J (2011). "Pelvic fractures: classification and nursing management". Nursing standard (Royal College of Nursing (Great Britain): 1987). 26 (10): 49-57.

Walker J. (2011). Pelvic fractures: classification and nursing management. Nursing standard (Royal College of Nursing (Great Britain), 26 (10): 49-57.

WHO, ed. (2013). Global Status Report on Road Safety 2013: supporting a decade of action (PDF) (official report). Geneva, Switzerland: World Health Organisation (WHO). pp. vii, 1-8, 53ff (countries), 244-251 (table A2), 296-303 (table A10). 


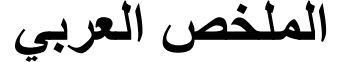

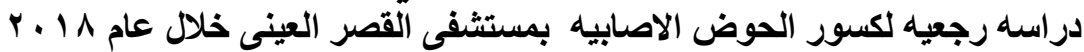

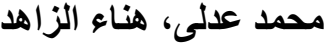

قسم الطب الثرعى والسموم الاكلينيكيه كلية الطب جامعة القاهرة

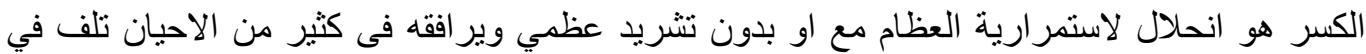

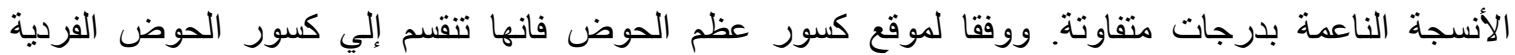
(كسرفردي لعظم الحوض)، وكسور الحوض المعقدة (كسر متعدد لعظم الحوض). و مو من الاسباب الثائعه لكسور

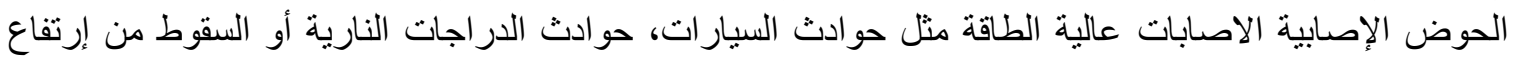
كبير يتم التشخيص علي اساس من التاريخ الطبي، الفحوصات الخاصة عادة ما تشمل الأشعة السينية والأشعة التشابه

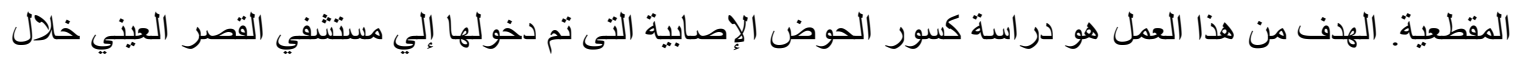

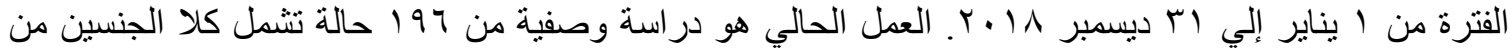

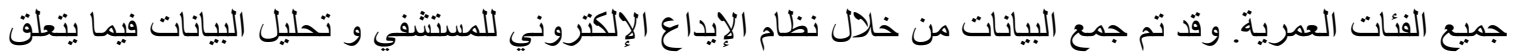

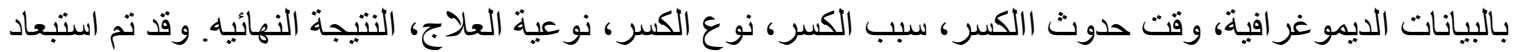

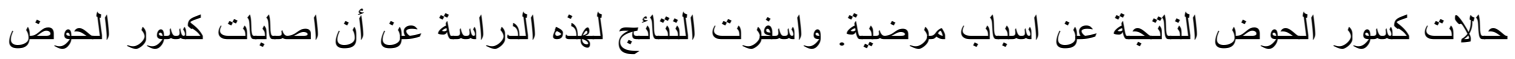
اعلى فى الفئه العمريه من اب إلى •ـ سنها، فى الذكور اعلى من الاناث، فى مناطق الحضر اعلى من المناطق

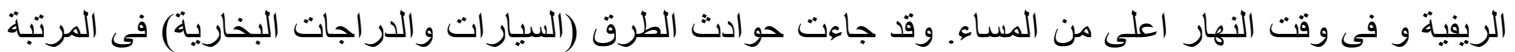

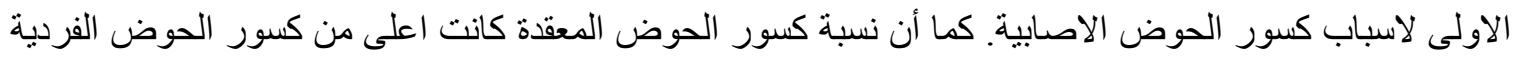
وكذلك كانت نسبة التدخل الجر احى اعلى من العلاج التحفظى فى حالات كسور الحوض بالمستشفى. وقد كان التحسن هو الغالب بنسبة كبيرة تقارب ^^^\% في حين ان نسبة الوفاه كانت ؟ب\% فقط وكانت مرتبطه فقط بالفئه العمرية اكثرمن ال7 سنه. 